\title{
A Diagnostic Model for Assessing the Knowledge Management Practices of Construction Firms
}

\author{
Serdar Kale* and Erkan A. Karaman**
}

Received January 27, 2011/Revised June 15, 2011/Accepted July 4, 2011

\begin{abstract}
Knowledge management is rapidly becoming a key organizational capability for creating competitive advantage in the construction industry. The emergence of knowledge management as a key organizational capability for creating competitive advantage poses enormous challenges to executives of construction firms. This paper proposes a model for benchmarking the knowledge management practices of construction firms that can guide and assist construction business executives to meet these challenges. The proposed model incorporates benchmarking and knowledge management concepts with Importance-Performance Analysis (IPA) and Comparative Performance Analysis (CPA) maps. The IPA and CPA maps are visual management tools that have been commonly used for continuous improvements in processes and the performance of firms. Yet they have not been used in the construction management literature or for evaluating the knowledge management practices. The proposed model can be used by construction firms as an internal performance measurement tool to evaluate their knowledge management practices. It can provide powerful diagnostic information to construction business executives of construction firms in order to evaluate their firm's knowledge management practices, identify their firm's comparative advantages and disadvantages with regard to each knowledge management practice, and set priorities for managerial actions related to knowledge management practices that need improvement. A real-world case study was conducted by administering a survey to 105 construction firms operating in Turkey and is presented to illustrate the implementation and utility of the proposed model.
\end{abstract}

Keywords: knowledge management, construction industry, performance, construction firms, benchmarking

\section{Introduction}

There is increasing recognition that knowledge management is a key organizational capability for creating and sustaining competitive advantage in today's construction business environment (e.g., Kululanga and McCaffer, 2001; Egbu, 2004; Carrillo and Chinowsky, 2006; Pathirage et al., 2007; Maqsood et al., 2007). This means that improving and enhancing this key organizational capability should be given high priority by business executives (Wen, 2009) and construction management researchers. Improving this organizational capability begins with the understanding and evaluation of firm knowledge management practices. Performance measurement models provide construction business executives with meaningful tools and techniques for understanding and evaluating their knowledge management practices. These tools and techniques would allow construction business executives to understand and evaluate and in turn improve their knowledge management practices. Some social actors (i.e., firms, institutional organizations, and researchers) have been involved in developing performance measurement models for evaluating the knowledge management practices of construction firms (e.g.,
Kululanga and McCaffer, 2001; Egbu, 2004; Samuelsson and Grans, 2004; Carrillo and Chinowsky, 2006; Kale, 2009). Despite the fact that these models represent an important milestone in the measurement and evaluation of knowledge management practices of construction firms, the utility of such models is severely limited due to the exclusion of the competitive environment (Chen et al., 2009) in which construction firms operate. This limitation of previously proposed models for evaluating the knowledge management practices of construction firms (e.g., Kululanga and McCaffer, 2001; Egbu, 2004; Yu et al., 2009; Kale, 2009; Arif et al., 2009) can be overcome using a benchmarking approach. Benchmarking is one of the most powerful performance modeling approaches that enables firms to include competitive dynamics in the evaluation process. The primary objective of benchmarking is continuous improvement through observing activities of other firms (Camp, 1989). Benchmarking has been a popular performance modeling approach in the construction management literature. It has been used for evaluating the success of selected design and build projects (Lam et al., 2004), improving total quality management initiatives of construction firms (Sommerville and Robertson, 2000), assessing construction safety management

\footnotetext{
*Professor, Dept. of Architecture, Izmir Institute of Technology, 35430, Izmir, Turkey (Corresponding Author, E-mail: serdarkale@iyte.edu.tr)

**Assistant Professor, Dept. of Civil Engineering, Balikesir University, 10145, Balikesir, Turkey (E-mail: ekaraman@balikesir.edu.tr)
} 
programs (Fang et al., 2004), and improving project management performance (Luu et al., 2008). Yet, evaluating the knowledge management practices of construction firms using a benchmarking approach remains relatively unexplored. The paper presented herein focuses on this relatively unexplored research area. It presents a simple framework for evaluating the knowledge management practices of construction firms. The proposed framework is a synthesis of benchmarking and knowledge management concepts. The main objectives of the proposed framework are (1) to assist executives of construction firms in identifying basic knowledge management practices and (2) to provide executives of construction firms with an internal reporting tool to use to evaluate and benchmark their firm's knowledge management practices.

\section{A New Challenge for Construction Firms}

Construction firms are now operating in a new era called knowledge economy. Knowledge is the primary resource for gaining and sustaining competitive advantage in this new era. Managing knowledge is quite different from managing other types of resources because of its intangible nature. Difficulties associated with managing knowledge as an intangible resource, coupled with the unique characteristics of the construction industry (i.e., project-based; knowledge-intensive; demand-driven; and horizontal fragmentation - i.e., different specialists involved in projects; and vertical fragmentation - i.e., different phases of a construction project) present a new challenge to construction firms. This new challenge has been given priority by the social actors (i.e., firms, institutional organizations, and researchers) of the construction industry. Some construction firms have been very keen in meeting this new challenge and have opted to develop and implement a "structured approach" (i.e., formal knowledge management systems) to manage their knowledge resources, whereas most construction firms have opted to adopt the "ad hoc approach" to manage their knowledge resources (Tan et al., 2010; Carrillo et al., 2004; Carrillo and Chinowsky, 2006). Several knowledge management techniques (i.e., lessons learned systems, post project reviews, communities of practices, training, forum, reassignment of people, mentoring) and technologies (i.e., groupware, expert directory, project extranet, podcasts social bookmarks, video sharing, social networks, blogs and micro-blogs) have been used by construction firms to acquire, disseminate, share, process and create new knowledge.

Public and private programs and initiatives have been launched under different names to assist firms in managing their knowledge resources. These include the Lessons Learned Program (LLP) and Best Practices (BP) developed by the Construction Industry Institute (CII), Measuring the Impact of Knowledge Management by the American Productivity and Quality Center (APQC), Value Improving Practices (VIP) by the Independent Project Analysis (IPA) and Benchmarking Knowledge Management Practice in Construction by Construction Industry Research and Information Association (CIRIA). This preceding list only covers the most widely cited programs and initiatives in the construction management literature (Cha and O'Connor, 2006; Carrillo and Chinowsky, 2006; Hwang et al., 2008; Caldas et al., 2009; Song et al., 2009).

Some construction management scholars have been also involved in developing model to assist construction firms in addressing this new challenge. The most notable models include Kamara et al.'s (2002) Cross-sectoral Learning in the Virtual Enterprise model (CLEVER); Robinson et al.'s (2004) Improving Management Performance through Knowledge Transformation model (IMPaKT); Robinson et al.'s (2005) StartupTakeoff-Expansion-Progressive-Sustainability model (STEPS); and Yu et al.'s (2009) Knowledge Value Adding Model (KVAM). The above mentioned models, programs and initiatives have provided important insight into the concept of knowledge management and how it can be measured and used for improvement in construction firms.

Previous research studies (Al-Ghassani et al., 2004; Carillo et al., 2004; Robinson et al., 2005; Carrillo and Chinowsky 2006; Fong and Chu 2006) have revealed that construction firms have encountered barriers in managing their knowledge resources. The major barriers to managing knowledge resources that emerged from these studies include inadequate understanding of knowledge management; lack of management support; inappropriate information and communication technology; organizational culture and structure; difficulty in communicating the benefits of knowledge management to employees; lack of resources (i.e., time and financial resources); difficulty measuring the value added; and a narrow organizational focus on knowledge management. Chinowsky and Carrillo (2008) proposed that construction firms could adopt a strategic approach to knowledge management to overcome these barriers. A diagnostic performance evaluation model that builds on a strategic approach to knowledge management can assist construction firms to overcome these barriers. The following section presents the conceptual foundations required for developing such a model.

\section{Knowledge Management: Conceptual Founda- tions}

The concept of knowledge and its management have been at the center stage in the management literature for over a decade (e.g., Nonanka, 1991; Drucker, 1998; Garvin, 1998; Hansen et al., 1999). Different definitions of knowledge prevail in the literature, primarily due to its multi-dimensionality. Davenport and Prusak (1998) define knowledge as "a fluid mix of framed experience, values, contextual information and expert insight that provides a framework for evaluating and incorporating new experiences and information." Dana et al. (2005) define knowledge as "the integration of information, ideas, experience, intuition, skills and lessons learned that creates added value for a firm." Nonaka et al. (1997) propose that "knowledge is a meaningful set of information that constitutes a justified true belief and/or embodied technical skill". The multi-dimensionality of 
knowledge has led scholars to classify it in different ways. Alavi and Leidner (2001) classify knowledge as declarative knowledge (know-about), procedural knowledge (know-how), causal knowledge (know-why), conditional knowledge (know-when), and relational knowledge (know-with). Matusik and Hill (1998) propose that knowledge can be classified as public knowledge and private knowledge. Zander and Kogut (1995) recommend it to be individual knowledge and collective knowledge. The most influential classification for knowledge is found in Nonaka (1991), who classifies knowledge into two groups: tacit knowledge and explicit knowledge. Tacit knowledge is difficult to express, personal (i.e., based on individual experiences), context driven and unorganized, whereas explicit knowledge can be easily codified by using symbolic representations (e.g., words and scientific formulas) and communicated.

The term "knowledge management" has entered to the lexicon of management and organizational studies since 1990s (Ishikawa and Naka 2007). Knowledge management refers to the creation and subsequent management of an environment that encourages knowledge to be created, shared, learned and organized for the benefit of the firm (Sarrafzadeh et al., 2006). The earliest research studies on knowledge management have been predominantly driven by technical perspective (i.e., information systems IS) (Hansen et al., 1999; Tuomi, 2002). Technical perspective primarily focuses on technical aspects (i.e., processes, tasks, and technology) of knowledge management. Subsequent recent research studies have shifted their focus from technical aspects of knowledge management to social aspects (i.e., relationships among people, attributes of people reward systems, and authority structures) of knowledge management (Tuomi, 2002). The contemporary research studies on knowledge management (Lee and Choi, 2003; Chuang, 2004) build on the social-technical perspective (i.e., a synthesis of social and technical perspectives). The central themes in these research studies have been (1) defining the concept of knowledge management effectiveness and (2) identifying the primary knowledge management practices that influence knowledge management effectiveness of the firms. The concept of knowledge management effectiveness can be better understood by defining the term effectiveness. The term effectiveness refers to the degree to which a process or practice realizes its goals (Daft, 1989). This definition implies that the goals of knowledge management should be also defined. The primary goal of knowledge management is to create and sustain competitive advantage (Wiig, 1997). Creating and sustaining competitive advantage means that a firm outperforms its rivals on some criteria, such as (1) financial perspective- profit, return on assets, return on investment; (2) process perspective - introducing innovative construction methods and contracting services, improving coordination and communication among project participants, reducing the cost of operations and processes, improving timelines for construction operations and processes, enhancing the quality of contracting services and constructed facilities, sharing best practices, lessons learned, techniques and processes for construction operations and their management, introducing innovative construction methods and contracting services; (3) market perspective - market share, growth in market share, identifying opportunities for new construction projects and markets; and (4) customer/client perspective - increasing client satisfaction.

Identifying the primary knowledge management practices that influence knowledge management effectiveness has been another central research issue in contemporary research studies (Lee and Choi, 2003; Chuang, 2004; Ghosh and Scott, 2007). The primary knowledge management practices that emerged from previous research studies include (1) knowledge management processes and (2) knowledge management enablers.

Different models (Nonaka, 1991; Wiig, 1993; Gold, 2001) have been proposed in the literature to explore the knowledge management process. A succinct review of these models reveals that they vary in their scope and level of detail. Nonaka's (1991) "knowledge spiral," which primarily focuses on how one form of knowledge (i.e., tacit knowledge or explicit knowledge) is exchanged and transformed into another form, decomposes this and proposes four sub-processes: (1) socialization, (2) externalization, (3) combination, and (4) internalization. Wiig's (1993) "knowledge cycles" model adopts a broader approach to the knowledge management process and proposes the following four sub-processes: (1) building, (2) holding, (3) pooling, and (4) applying knowledge. Wiig's (1993) model focuses on how knowledge is created and subsequently used by individuals or organizations. Gold et al. (2001) adopts a much broader approach then Wiig (1993) and proposes four sub-knowledge management processes: (1) acquisition, (2) conversion, (3) application, and (4) protection. Lin (2007) considers the scope of Gold et al. (2001) to be sufficiently broad to provide a complete analysis of the knowledge management process. The research presented here uses Gold et al.'s (2001) knowledge management process model. The knowledge acquisition process involves searching for and finding entirely new knowledge or creating new knowledge out of existing knowledge through collaboration (Inkpen 1996). The knowledge application process involves the utilization of knowledge for improving efficiency and effectiveness of activities and operations. The knowledge conversion process involves the transfer of knowledge among the social actors (i.e., departments, groups and individuals). The knowledge protection process involves securing and protecting knowledge from inappropriate and illegal use or theft.

Knowledge management enablers are the organizational mechanisms that stimulate creating and developing knowledge within an organization and also facilitate its sharing, diffusion and protection (Lee and Choi, 2003). They provide a foundation on which effective knowledge management can be built. Knowledge management enablers can be decomposed into two groups (Chuang, 2004): technical knowledge management enablers and social knowledge management enablers.

Technical knowledge enablers include a number of Information and Communication Technologies (ICT) such as data processing, storage, communication, and management information systems used by the firm to support and enhance the creation, storage/ 
retrieval, transfer, application, sharing of organizational knowledge. Information and communication technologies constitute the technical infrastructure that enables firms to (1) facilitate the rapid collection, storage, and exchange of knowledge, (2) integrate fragmented flows of knowledge and (3) convert and create new knowledge (Chuang, 2004).

Social knowledge management enablers involve the sum of the actual and potential resources available that derive from the relationships and interactions of social actors (i.e., individual, department and firm) (Nahapiet and Ghoshal, 1998). Some scholars (Gold et al., 2001; Chuang, 2004) decompose them into two components: (1) organizational culture and (2) organizational structure.

Organizational culture includes a set of values, norms beliefs, expectations and assumptions that is widely shared in an organization (Huber 2001). Drucker et al. (1996) consider organizational culture as the "corporate glue" that binds social actors to the goal and objectives of the organization. This 'corporate glue' informally shapes the values, assumptions, beliefs, and behaviors of the social actors that could encourage or impede the creation, sharing and diffusion of organizational knowledge. Previous research studies (Chen and Huang, 2007; Nayir and Uzuncarsili, 2008) suggest that openness, mutual trust, and collaboration are the three essential components of organizational culture that influence knowledge management activities. A sense of openness in an organization enhances social interactions among social actors and in turn motivates social actors to share their ideas, insights, and knowledge. It eliminates barriers that inhibit effective knowledge exchange and facilitates substantial and influential knowledge exchange among employees. A sense of strong mutual trust increases the commitment of social actors to organizational goals and reduces their fears. Finally, a sense of strong collaboration creates an environment where social actors willingly cooperate with each other instead of simply working together not because they are forced to do so. Such an environment encourages social actors to discuss their work with other colleagues and to ask others for assistance when needed, and leads to high levels of participation in the processes of capturing and transferring knowledge.

Organizational structure can be considered a social architecture of roles and flows of authority, work materials, information, and decision-making processes that make up an organization (Pennings, 1992). It provides a social framework for the transformation of inputs (i.e., human, capital, physical and knowledge resources) into outputs (i.e., contracting service, constructed facility). This social framework formally shapes the behaviors of social actors and acts as an information and knowledge filter that can limit what a social actor sees in its operating environment (Cortes et al., 2007), and influence how a social actor perceives and interprets its environment. Therefore, organizational structure can facilitate or inhibit knowledge management behaviors and in turn knowledge management effectiveness. Some researchers (Chuang, 2004; Cortes et al., 2007) argue that competing in today's business environment requires an organizational structure that (1) encourages sharing knowledge and collaboration with regard to knowledge across boundaries, (2) facilitates the creation and the discovery of new knowledge, (3) promotes collective rather than individualist behavior, and (4) enables knowledge exchange between social actors to solve new problems.

\section{Model Development}

The knowledge management evaluation model proposed in this paper builds on the concepts that have been set forth by benchmarking (Camp, 1989), knowledge management models (Gold et al., 2001; Lee and Choi, 2003), Importance-Performance Analysis (IPA) maps (Martilla and James, 1977), and Comparative Performance Analysis (CPA) maps (Deng et al., 2008). It involves a five-step procedure for evaluating the knowledge management practices of construction firms. These steps are as follows: Step 1. Identifying evaluation criteria for the knowledge management practices of construction firms. Step 2. Rating the knowledge management practices of construction firms. Step 3. Deriving the importance weights of knowledge management practices. Step 4. Constructing an Importance-Performance Analysis (IPA) map for the benchmarked firm(s). Step 5. Constructing a Comparative Performance Analysis (CPA) map for the benchmarked firm(s).

\subsection{Step 1. Identifying Knowledge Management Practices for Benchmarking}

The first step in evaluating the knowledge management practices of construction firms is identifying the knowledge management practices $\left(\mathrm{C}_{\mathrm{i}}\right)$ that would be used during the benchmarking process. Different knowledge management models (e.g., Gold et al., 2001; Lee and Choi, 2003) have been set forth in the literature. The preceding section reveals that the most important knowledge management practices $\left(\mathrm{C}_{\mathrm{i}}\right)$ that influence a firm's Knowledge Management Effectiveness (KME) include organizational culture $\left(\mathrm{C}_{1}\right)$, organizational structure $\left(\mathrm{C}_{2}\right)$, information and communication technology $\left(\mathrm{C}_{3}\right)$, knowledge acquisition $\left(\mathrm{C}_{4}\right)$, knowledge conversion $\left(\mathrm{C}_{5}\right)$, knowledge application $\left(\mathrm{C}_{6}\right)$, and knowledge protection $\left(\mathrm{C}_{7}\right)$.

\subsection{Step 2. Rating Knowledge Management Practices of Construction Firms}

The second step is rating the knowledge management practices $\left(\mathrm{C}_{\mathrm{i}}\right)$ of construction firms. A construction firm's knowledge management practices can be evaluated by using a two-stage process: (1) developing a set of multi-item scales for measuring each knowledge management practice and (2) rating the construction firm's level of achievement with regard to each item by using Likert-type scales. A construction firm's performance rating for each knowledge management practice $\left(\mathrm{R}_{\mathrm{i}}\right)$ is derived by summing up the corresponding responses and calculating the mean.

The rationale behind using multi-items, instead of a single item, for measuring knowledge management practices $\left(\mathrm{R}_{\mathrm{i}}\right)$ and Knowledge Management Effectiveness (KME) is to reduce the 
measurement errors that weaken the relationships among research constructs and, in turn, enhance the reliability of the rating process. Individual items have considerable measurement errors, hence, taking the average of several items designed to measure the research constructs is one way to address the measurement error issues. This process of summing a set of items and averaging them into a single composite score tends to provide a more reliable measure of a construct than a single item (Ghiselli et al., 1981).

The questionnaire survey method can be used to collect data on construction firms' performance ratings for knowledge management practices $\left(\mathrm{R}_{\mathrm{i}}\right)$.

\subsection{Step 3. Deriving the Importance Weights of Knowledge Management Practices}

The third step involves identifying the importance weight of each knowledge management practice $\left(\mathrm{W}_{\mathrm{i}}\right)$. The importance weights of knowledge management practices can be determined by using a stated approach (i.e., explicit approach) or a derived approach (i.e., implicit approach). The stated approach involves judging the importance of a knowledge management practice with linguistic variables such as low importance, moderate importance, and very high importance. On the other hand, the derived approach involves use of quantitative methods such as correlation analysis or multiple regression analysis. The derived approach is argued to be better than the stated approach because its use brings objectivity to the evaluation process and eliminates biases (Garver, 2003). Furthermore, the stated approach lacks in the ability to differentiate between importance weights of evaluation criteria (Garver, 2003). The model presented in this paper uses a derived approach to determine importance weights $\left(\mathrm{W}_{\mathrm{i}}\right)$ of the evaluation criteria. The process of implicitly deriving the importance weights of knowledge management practices $\left(\mathrm{W}_{\mathrm{i}}\right)$ used in this study involves the use of correlation analyses. The rationale behind this choice is the fact that a multiple regression analysis is prone to the problem of multicolinearity that would suppress or inflate importance weight of a criterion. Correlation analysis is immune to the problem of multicolineairty.

The importance weight of $i$ th knowledge management practice can be derived by conducting a correlation analysis between the performance rating of $i$ th knowledge management practice $\left(\mathrm{R}_{\mathrm{i}}\right)$ and the Knowledge Management Effectiveness (KME). The implicitly derived approach used in the proposed model (i.e., correlation analysis), like any other previously proposed benchmarking models (e.g., Deng et al., 2008), rests on the assumptions that 'knowledge management practices $\left(\mathrm{R}_{\mathrm{i}}\right)$ are positively related to Knowledge Management Effectiveness (KME)' and 'the higher the correlation coefficient, the more important is the knowledge management practice'. There is overwhelming empirical and anecdotal evidence in the literature (e.g., Gold et al., 2001; Chuang, 2004; Cortes et al., 2007; Nayir and Uzuncarsili 2008) that supports the validity of these assumptions.

Knowledge Management Effectiveness (KME) of construction firms can similarly be measured by following the very same pro- cedure used in rating knowledge management practices of construction firms (i.e., developing questionnaire and conducting a questionnaire survey) (See Step 2).

\subsection{Step 4. Constructing the Importance - Performance Analysis (IPA) Map}

The fourth step in benchmarking knowledge management practices involves selecting a construction firm to be benchmarked (i.e., case firm) and creating the Importance-Performance Analysis (IPA) map for the case firm. The IPA map is a two dimensional grid that combines the importance weights and performance ratings of knowledge management practices (Martilla and James, 1979). The horizontal axis of (x-axis) of this two dimensional grid indicates the implicitly derived importance weights $\left(\mathrm{W}_{\mathrm{i}}\right)$ of knowledge management practices and the vertical axis (y-axis) represents the mean values of performance ratings $\left(\mathrm{R}_{\mathrm{i}}\right)$ for knowledge management practices (Fig. 1). The IPA map consists of four quadrants. Each of the quadrants is a combination of importance $\left(\mathrm{W}_{\mathrm{i}}\right)$ and performance ratings of knowledge management practices $\left(\mathrm{R}_{\mathrm{i}}\right)$. Quadrant I (high importance /high performance) indicates knowledge management practice(s) that can be major strength(s) for the construction firm. Therefore, the construction firm should maintain its position on each knowledge management practice located in this quadrant. Quadrant II (low importance/high performance) features knowledge management practice(s) that can be re-organized or re-structured in order to direct firm's efforts and resources to the other knowledge management practices that need improvement. Quadrant III (low importance/low performance) holds the knowledge management practices that need no immediate action. Each knowledge management practice located in this quadrant should be closely monitored because a change in the importance of this knowledge management practice could turn it into a major weakness for the construction firm. Quadrant IV (high importance/low performance) represents the knowledge management practices that are

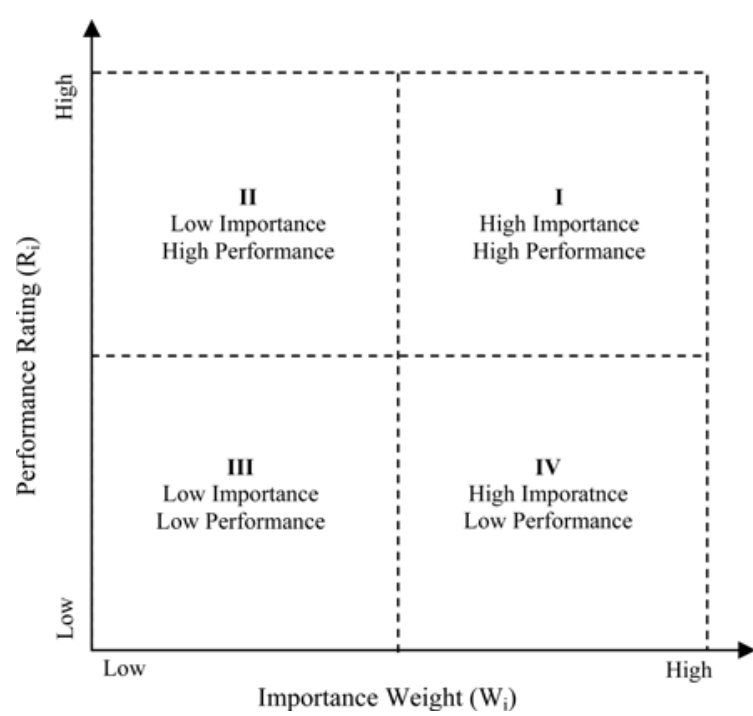

Fig. 1. Importance - Performance Analysis (IPA) Map 
the construction firm's major weakness(es). Each knowledge management practice located in this quadrant needs immediate corrective action. Therefore, the construction firm should focus on improving each knowledge management practice located in this quadrant.

\subsection{Step 5. Constructing the Comparative Performance Analysis (CPA) Map}

The final step in benchmarking the knowledge management practices is constructing the Comparative Performance Analysis (CPA) map for the case firm (i.e., firm to be benchmarked). The CPA map visualizes the case firm's performance ratings of knowledge management practices $\left(\mathrm{R}_{\mathrm{i}}\right)$ compared to the those of its primary rivals, the average or best of the benchmarked construction firms. The comparative performance analysis map is a two dimensional grid (Fig. 2). The horizontal axis indicates the case firm's Comparative Performance Ratios $\left(\mathrm{CPR}_{\mathrm{i}}\right)$ of knowledge management practices and the vertical axis represents the case firm's performance ratings of knowledge management practice.

Different comparative performance ratios (e.g., Garver, 2003; Deng et al., 2008) such as (1) ratio of the case firm's performance ratings to the average performance rating of its primary rivals, (2) ratio of the case firm's performance ratings to the average performance ratings of all benchmarked firms, (3) ratio of the case firm's performance ratings to the performance ratings of the best construction firm involved in the benchmarking process, have been proposed for constructing CPA maps. The comparative performance ratios $\left(\mathrm{CPR}_{\mathrm{i}}\right)$ used in this paper are calculated in Eq. (1) by dividing the case firm's performance rating $\left(\mathrm{R}_{\mathrm{i}}\right)$ for a given knowledge management practice $\mathrm{C}_{\mathrm{i}}$ by the average performance rating $\left(A v R_{i}\right)$ for that knowledge management practice $\left(\mathrm{C}_{\mathrm{i}}\right)$ of all construction firms involved in the benchmarking process (Deng et al., 2008):

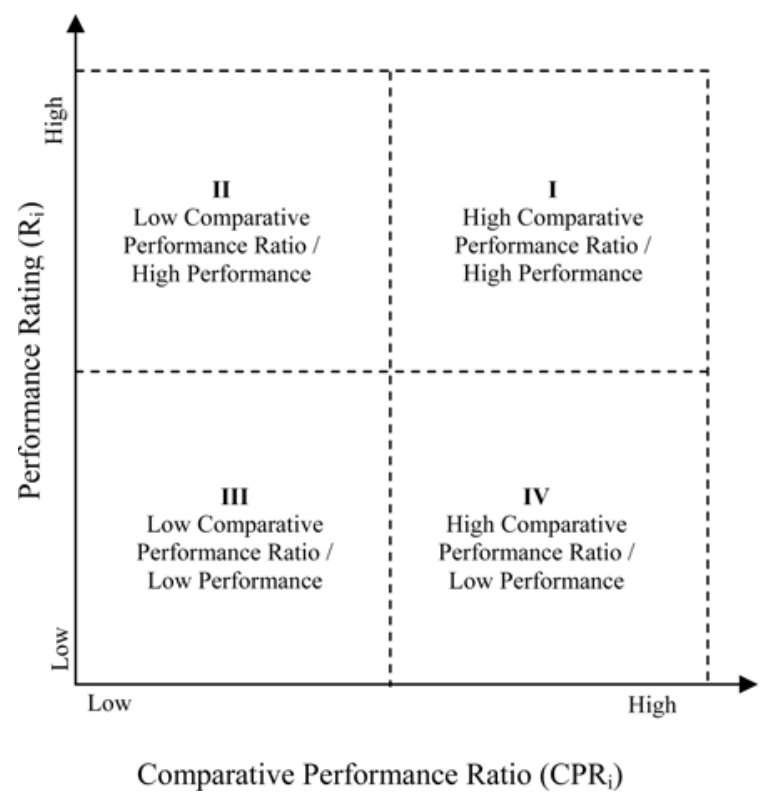

Fig. 2. Comparative Performance Analysis (CPA) Map

$$
C P R_{i}=\frac{R_{i}}{A v R_{i}}
$$

Values of $\mathrm{CPR}_{\mathrm{i}}$ greater than $1\left(\mathrm{CPR}_{\mathrm{i}}>1\right)$ suggest that the case firm has a comparative advantage in $i$ th knowledge management practice $\left(\mathrm{C}_{\mathrm{i}}\right)$. On the other hand, for values of $\mathrm{CPR}_{\mathrm{i}}$ less than 1 $\left(\mathrm{CPR}_{\mathrm{i}}<1\right)$ suggest that the case firm has a comparative disadvantage in $\mathrm{i}$ th knowledge management practice $\left(\mathrm{C}_{\mathrm{i}}\right)$. Finally, when the value of $\mathrm{CPR}_{\mathrm{i}}$ equals $1\left(\mathrm{CPR}_{\mathrm{i}}=1\right)$, the case firm's performance rating for the $i$ th knowledge management practice equals the mean of all the firms (i.e., industry average). The knowledge management practice that has a $\mathrm{CPR}_{\mathrm{i}}$ ratio of 1 is said to be source of competitive parity.

The CPA map used for benchmarking the knowledge management practices of construction firms consists of four quadrants. Each quadrant is a combination of comparative performance ratios and performance ratings of knowledge management practices. Quadrant I (high comparative performance ratio/high performance) indicates knowledge management practice(s) that can be a source of competitive advantage for the case firm. Quadrant II (low comparative performance ratio/high performance) represents knowledge management practice(s) where the case firm performs high but lower than its rivals. The case firm is facing intense competition with regard to the knowledge management practices located in this quadrant. Yet the case firm is struggling to cope with this intense competition. Quadrant III (low comparative performance ratio/low performance) indicates knowledge management practice(s) where the case firm performs poorly on both aspects (i.e., comparative performance ratio and performance). Knowledge management practices located in Quadrant III can be sources of competitive disadvantage for the case firm. Quadrant IV (high comparative performance ratio/low performance) points to the knowledge management practice(s) where the case firm performs poorly but better than its rivals. Knowledge management practices located in this quadrant need to be closely monitored because they can be source of competitive advantage or competitive disadvantage.

\section{Research Methodology}

The application of the benchmarking model proposed in the preceding section involves a three-stage process. The first stage involves collecting data on the performance ratings of knowledge management practices $\left(\mathrm{R}_{\mathrm{i}}\right)$ and the Knowledge Management Effectiveness (KME) of construction firms in order to derive the importance weights of the knowledge management practices $\left(\mathrm{W}_{\mathrm{i}}\right)$ of construction firms. The second stage involves selecting a construction firm to be benchmarked (i.e., case firm). The third stage involves creating IPA and CPA maps for the knowledge management practices of the case firm.

\subsection{Sample and Data Collection}

A sample of 300 construction firms was constructed using directories and online databases to illustrate the application of the 
proposed model. Different formal and informal communication channels were used to reach these construction firms and request their participation in the survey. The final sample used in benchmarking size decreased from 300 to 105 construction firms because some of the construction firms could not be contacted, some others declined to participate, and still other agreed to participate but failed to provide the requested information in a timely or complete manner. Table 1 presents the age and size profile of the construction firms surveyed.

The key informants who participated in the application of the proposed model were top executives at construction firms such as presidents, vice presidents or chief executive officers. These individuals were considered to be the most knowledgeable persons regarding their firm's knowledge management practice ratings $\left(\mathrm{R}_{\mathrm{i}}\right)$ and Knowledge Management Effectiveness (KME).

A questionnaire entitled Knowledge Management Benchmarking Instrument (KMB-I) was prepared based on a succinct review of previous research studies on knowledge management (Gold et al., 2001; Lee and Choi, 2003). KMB-I consists of two parts. The first part of the KMB-I includes a series of open-ended questions that solicit demographic information on the surveyed construction firms. The second part of KMB-I includes a set of

Table 1. Demographic Characteristics of Surveyed Construction Firms ( $\mathrm{N}=105)$

\begin{tabular}{c|c|c|c}
\hline $\begin{array}{c}\text { Size (Number of } \\
\text { Employees) }\end{array}$ & $\begin{array}{c}\text { Number of } \\
\text { Firms. }\end{array}$ & $\begin{array}{c}\text { Percentage } \\
(\%)\end{array}$ & $\begin{array}{c}\text { Cumulative } \\
\text { Percentage }\end{array}$ \\
\hline $20-40$ & 35 & $33 \%$ & $33 \%$ \\
\hline $41-60$ & 7 & $7 \%$ & $40 \%$ \\
\hline $61-100$ & 11 & $10 \%$ & $50 \%$ \\
\hline $101-200$ & 15 & $14 \%$ & $65 \%$ \\
\hline $201-500$ & 20 & $19 \%$ & $84 \%$ \\
\hline Over 500 & 17 & $16 \%$ & $100 \%$ \\
\hline Firm Age & & & \\
\hline $1-10$ & 18 & $17 \%$ & $17 \%$ \\
\hline $11-20$ & 22 & $21 \%$ & $38 \%$ \\
\hline $21-30$ & 26 & $25 \%$ & $63 \%$ \\
\hline $31-40$ & 17 & $16 \%$ & $79 \%$ \\
\hline $41-50$ & 15 & $14 \%$ & $93 \%$ \\
\hline $51-60$ & 4 & $4 \%$ & $97 \%$ \\
\hline $61-70$ & 3 & $3 \%$ & $100 \%$ \\
\hline
\end{tabular}

items for evaluating construction firms' knowledge management practices $\left(\mathrm{R}_{\mathrm{i}}\right)$ and their Knowledge Management Effectiveness (KME). Knowledge management effectiveness was measured from process perspective. On the second part of the evaluation form, the respondents were instructed to rate the extent to which they agreed with each item on a seven-point Likert type scale that ranged from " $1=$ strongly disagree" to " $7=$ strongly agree". Items used for measuring knowledge management practices $\left(\mathrm{R}_{\mathrm{i}}\right)$ and knowledge management performance (KME) were taken from Gold et al.'s (2001) study. The wording of the items was slightly modified to adapt them to the construction industry context. Appendix presents a sample of the multi-item scales used to measure knowledge management practices $\left(\mathrm{R}_{\mathrm{i}}\right)$ and Knowledge Management Effectiveness (KME).

\subsection{Methods}

The reliability of the multi-item scales used to measure the performance ratings for knowledge management practices $\left(\mathrm{R}_{\mathrm{i}}\right)$ and the Knowledge Management Effectiveness (KME) is assessed by the Cronbach's alpha coefficient method. The Cronbach's alpha coefficients of the multi-item scales (i.e., $\mathrm{R}_{\mathrm{i}}$ and $\mathrm{KME}$ ) are above the threshold of 0.70 recommended by Nunnally (1979) (Table 2). Therefore, it is concluded that the multi-item scales used to measure the performance ratings of knowledge management practices $\left(\mathrm{R}_{\mathrm{i}}\right)$ and the Knowledge Management Effectiveness (KME) are reliable. Table 2 presents the means of performance ratings of knowledge management practices $\left(\mathrm{R}_{\mathrm{i}}\right)$. The mean of performance ratings for knowledge management practices of the surveyed construction firms range from a high of 5.79 to a low of 4.54. The grand mean of performance ratings for the knowledge management practices of the surveyed construction firms (MR) is 5.38 .

The benchmarking model proposed in this paper implicitly derives the importance weight $\left(\mathrm{W}_{\mathrm{i}}\right)$ of each of the knowledge management practices by using correlation analysis. Table 2 presents correlation coefficients between the performance ratings of knowledge management practices $\left(\mathrm{R}_{\mathrm{i}}\right)$ and the Knowledge Management Effectiveness (KME). These correlation coefficients represent the derived importance weights of the knowledge management practices $\left(\mathrm{W}_{\mathrm{i}}\right)$. All correlation coefficients are positive

Table 2. Cronbach's Alpha Coefficients, Importance Weights, Performance Ratings, and Comparative Performance Rating Ratios

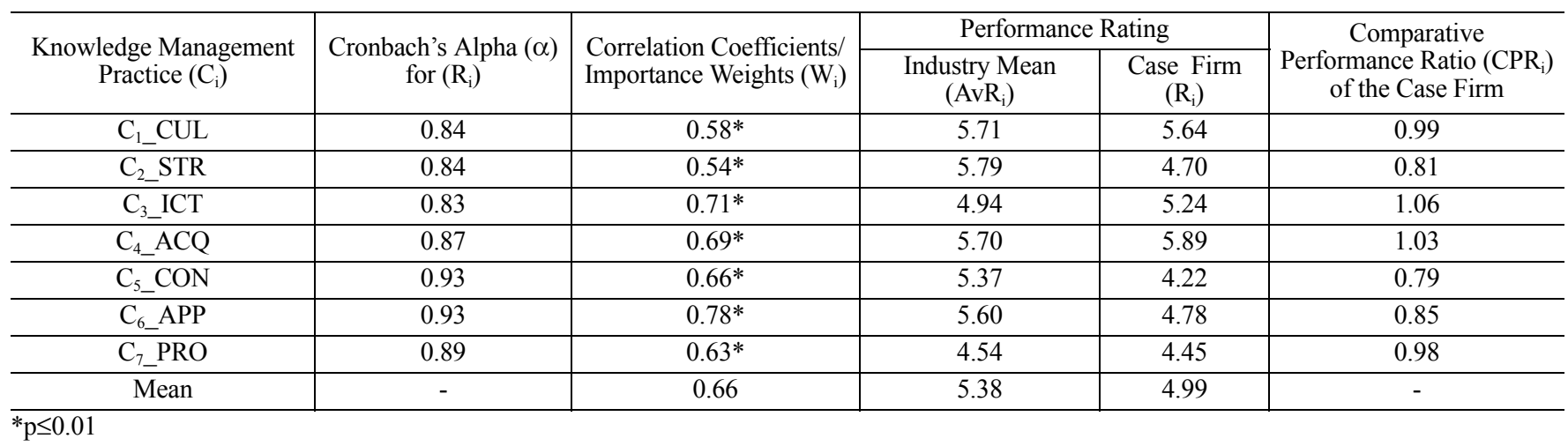


and statistically significant at $0.01(\mathrm{p} \leq 0.01)$. The results suggest that the most important knowledge management practice for construction firms is their knowledge application process $\left(\mathrm{W}_{6}=\right.$ $0.78, \mathrm{p} \leq 0.01$ ), whereas the least important knowledge management practice for construction firms is their organizational structure $\left(\mathrm{W}_{2}=0.54, \mathrm{p} \leq 0.01\right)$. The mean of the implicitly derived importance weights (MW) of knowledge management practices is 0.66 (Table 2).

\section{Model Application}

A construction firm was randomly selected as the case firm (i.e. the firm to be benchmarked) in this study to illustrate the use of the proposed model, which is a common research approach used in previous performance measurement modeling studies in the construction management domain (Samuelsson and Grans 2004; Kamara et al., 2002). The case firm is based in Istanbul, Turkey. It has more than 200 full time employees. Its turnover was over $\$ 175$ million in 2009 . It generally undertakes infrastructure and general building projects.

\subsection{Constructing the IPA Map for the Case Firm}

The horizontal and vertical axes of the IPA map are the implicitly derived importance weight of knowledge management practices $\left(\mathrm{W}_{\mathrm{i}}\right)$ and the case firm's performance rating of knowledge management practices, respectively. The case firm's performance ratings for knowledge management practices $\left(\mathrm{R}_{\mathrm{i}}\right)$ are presented in Table 2. The case firm's knowledge acquisition process has the highest performance rating $\left(\mathrm{R}_{4}=5.89\right)$ whereas its knowledge conversion process has the lowest performance rating $\left(\mathrm{R}_{5}=4.22\right)$. The grand mean of performance ratings of knowledge management practices of the case firm $\left(\mathrm{MR}_{\text {Case }}\right)$ is 4.99 .

The IPA map for the case firm is presented in Fig. 3. It was

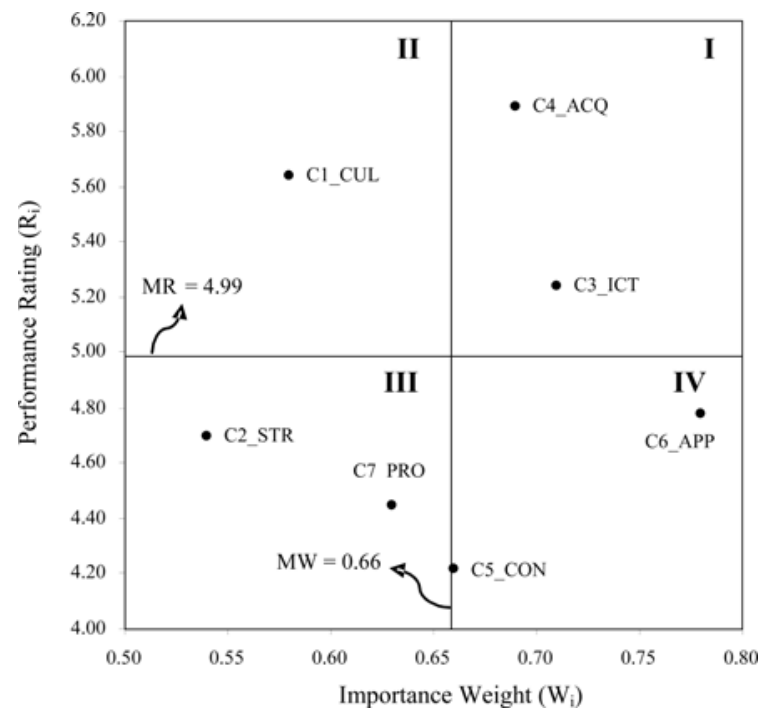

Fig. 3. Importance - Performance Analysis (IPA) Map for the Case Firm constructed by drawing two lines ( $\mathrm{MW}=0.66$ and $\mathrm{MR}=4.99$ ) that are perpendicular to the axes. The first line represents the mean of implicitly derived importance weight $(\mathrm{MW}=0.66)$ of knowledge management practices. The second line represents the grand mean performance rating of knowledge management practices of the case firm $\left(\mathrm{MR}_{\text {Case }}=4.99\right)$.

The IPA map provides several important insights for prioritizing and developing action plans for improving knowledge management practices of the case firm. First, the knowledge application process $\left(\mathrm{C}_{6}\right)$ of the case firm is located in the immediate action quadrant (i.e., Quadrant IV). It has the highest priority for immediate managerial action. Second the knowledge conversion process $\left(\mathrm{C}_{5}\right)$ of the case firm is located on the mean of implicitly derived importance weight line ( $\mathrm{MW}=0.66$ ). Therefore, it has the second highest priority for managerial action because a slight increase in the mean of importance weight (MW) or in importance weight of knowledge conversion process $\left(\mathrm{W}_{5}\right)$ could move it to Quadrant IV. The organizational structure $\left(\mathrm{C}_{2}\right)$ and the knowledge protection process $\left(\mathrm{C}_{7}\right)$ of the case firm are located in Quadrant III. They have relatively lower priority for managerial action despite the fact that the case firm performs poorly on both of these knowledge management practices. The organizational culture $\left(\mathrm{C}_{1}\right)$ of the case firm is located in Quadrant II. Information and communication technology $\left(\mathrm{C}_{3}\right)$ and the knowledge acquisition process $\left(\mathrm{C}_{4}\right)$ of the case firm are located in Quadrant I. The case firm should maintain its good performance on both of these knowledge management practices.

\subsection{Constructing the CPA Map for the Case Firm}

The $\mathrm{x}$-axis of the CPA map is comparative performance rating ratio (Fig. 4). Therefore, the comparative performance rating ratios $\left(\mathrm{CPR}_{\mathrm{i}}\right)$ with respect to each knowledge management practice of the case firm were calculated using Eq. (1). Table 2 presents the comparative performance ratios $\left(\mathrm{CPR}_{\mathrm{i}}\right)$ for each

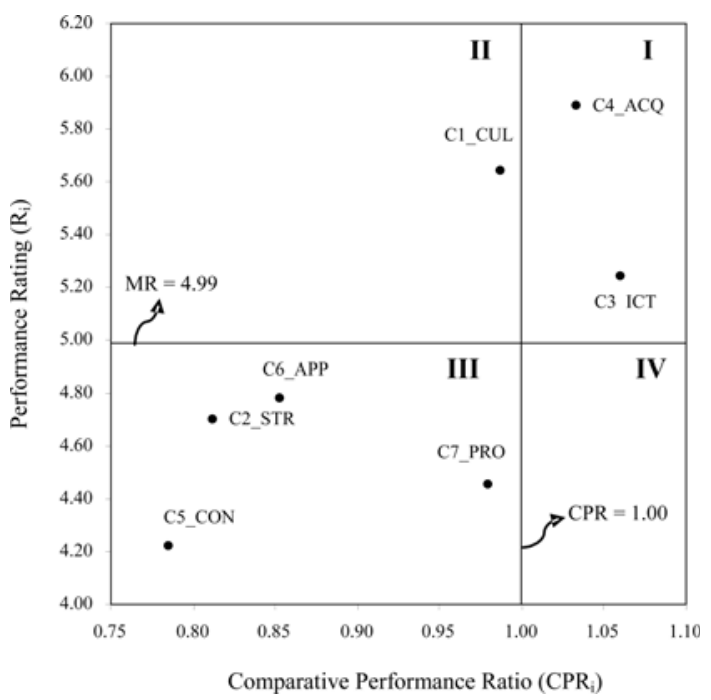

Fig. 4. Comparative Performance Analysis (CPA) Map for the Case Firm 
knowledge management practice of the case firm. The y-axis of the CPA map is the case firm's performance ratings for knowledge management practices. The case firm's performance ratings for each knowledge management practice are presented in Table 2. The X-axis of the CPA map presented in Figure 4 is divided into two areas by drawing a vertical line representing a comparative performance ratio of $1(\mathrm{CPR}=1)$. The areas left of the line $(\mathrm{CPR}=1)$ represent the case firm's competitive disadvantages in its knowledge management practices, whereas the areas right of the line represents its competitive advantages. Similarly, the y-axis of the CPA map is divided into two areas by a line representing the grand mean of performance ratings $(\mathrm{MR}=$ 4.99). The areas above of this line indicate the case firm's performance rating for a given knowledge management practice is higher than average performance ratings of its knowledge management practices whereas the areas below of this line indicate its performance rating for a knowledge management practice is below its average performance ratings of knowledge management practices.

The visual inspection of the CPA map of the case firm reveals several important issues (Fig. 4). First, the case firm performs above industry average $\left(\mathrm{CPR}_{\mathrm{i}}=1\right)$ on two knowledge management practices. Information and communication technology $\left(\mathrm{CPR}_{3}=1.06>1\right)$ and the knowledge acquisition process $\left(\mathrm{CPR}_{4}\right.$ $=1.03>1$ ) of the case firm are located in Quadrant $I$. These two knowledge management practices are the major comparative advantages of the case firm. It appears that information and communication technology of the case firm creates a supportive environment for its employees to engage in knowledge management activities. Furthermore, the case firm's performance rating for the knowledge acquisition process $\left(\mathrm{R}_{4}=5.89\right)$ is above the industry average performance rating $\left(\mathrm{AvR}_{4}=5.70\right)$. Second, the case firm performs below industry average $\left(\mathrm{CPR}_{\mathrm{i}}=1\right)$ on five knowledge management practices. The organizational structure $\left(\mathrm{C}_{2}\right)$, the knowledge conversion process $\left(\mathrm{C}_{5}\right)$, and the knowledge application process $\left(\mathrm{C}_{6}\right)$ are major comparative disadvantages whereas the knowledge protection process $\left(\mathrm{C}_{7}\right)$ is the minor comparative disadvantage of the case firm.

Combining insights gained from the IPA and the CPA maps (Figs. 3 and 4) reveal several important managerial issues. First, the comparative performance ratio of the knowledge application process $\left(\mathrm{C}_{6}\right)$ of the case firm is less than $1\left(\mathrm{CPR}_{6}=0.85<1\right)$. Yet the knowledge application process has the highest importance weight $\left(\mathrm{W}_{6}=0.78\right)$. Therefore, the highest priority for immediate managerial action for the case firm is its knowledge application process $\left(\mathrm{C}_{6}\right)$. Second, the knowledge conversion process $\left(\mathrm{C}_{5}\right)$ of the case firm has the smallest comparative performance ratio $\left(\mathrm{CPR}_{5}=0.79\right)$. The importance weight of the knowledge conversion process $\left(\mathrm{W}_{6}=0.66\right)$ is equal to the mean of importance weights $(\mathrm{MW}=0.66)$. The case firm should seek means to enhance its comparative performance ratio for the knowledge conversion process because a slight increase in the importance weight of this knowledge management practice can turn it into a source of competitive disadvantage. Third, the comparative per- formance ratio of the organizational culture $\left(\mathrm{CPR}_{1}=0.99\right)$ of the case firm and the knowledge protection process $\left(\mathrm{CPR}_{7}=0.98\right)$ are slightly smaller than industry average $(\mathrm{CPR}=1)$. These two knowledge management practices can be considered sources of competitive parity for the case firm. Therefore, the case firm should closely monitor its organizational culture $\left(\mathrm{C}_{1}\right)$ and its knowledge protection $\left(\mathrm{C}_{7}\right)$.

A post-study interview with the construction firms' executives was conducted to verify the results of the proposed model. The executives considered whether the proposed model offers a practical and useful procedure to evaluate and, in turn, improve their knowledge management practices. They agreed that the power of the model is its ability: (1) to provide a structured approach for understanding and evaluating knowledge management performance and (2) to pinpoint where their strengths and weaknesses lay in knowledge management practices. The executives of the case study firm indicated that they would initiate a managerial improvement plan based on the benchmarking study results.

\section{Conclusions}

There is increasing recognition that knowledge management is a key organizational capability for construction firms in today's business environment. Therefore construction firms should develop or adopt models, tools, and techniques that can enable them to evaluate and improve their knowledge management practices. The research presented here proposes a performance evaluation model in order to address these issues. It builds on concepts set forth by benchmarking, knowledge management models, Importance-Performance Analysis (IPA) map and Comparative Performance Analysis (CPA) map. The model proposed in this paper includes two simple visual tools that can be easily used by construction business executives but capable of providing powerful diagnostic information on construction firms' knowledge management practices. The model proposed in this paper has several practical implications for construction firms. First, the proposed model can be used by construction firms as an internal performance measurement tool for evaluating their knowledge management practices. Second, it empirically derives the importance weights of knowledge management practices. Empirically derived importance weights for knowledge management practices can be used by construction firms to evaluate their knowledge management practices. Third, the proposed model builds on comparative performance ratios computed by dividing the case firm's performance on each knowledge management practice by the industry averages and hence it brings competitive dynamics into the realm of performance evaluation. Therefore it can provide structural guidance to construction firms in identifying knowledge management practices that can be sources of competitive advantage or disadvantage. Fourth, the proposed model can guide construction firms in developing priorities for managerial action plans and interventions for knowledge management practices that need immediate improvement. Furthermore, 
the proposed model can assist construction business executives in pinpointing those areas that need improvement if they are to to succeed in the future. Finally, the proposed model can be used by construction firms to identify areas of wasted efforts and/or overinvestment keeping in mind that construction firms like other firms, have limited resources (i.e., financial, human, time, and knowledge) and that the effective and efficient use of resources is the key to outperforming rivals. The Importance Performance Analysis (IPA) and Comparative Performance Analysis (CPA) maps presented in this paper are based on the perceptions of Turkish construction business executives and correlation analysis. The primary objective of the study was to develop a model to benchmark knowledge management practices of construction firms. Explaining the casual relationship between knowledge management practices $\left(\mathrm{C}_{\mathrm{i}}\right)$ and knowledge management practices (KME) is beyond the scope of the research. Construction firms operating in the Turkish construction industry can use the implicitly derived importance weights presented in this paper to construct their own importance - performance analysis (IPA) and comparative performance analysis (CPA) maps. But implicitly derived importance weights and industry average performance ratings for knowledge management practices should be used with caution because they can vary from country to country.

\section{References}

Alavi, M. and Leidner, D. E. (2001). "Review: Knowledge management and knowledge management systems: Conceptual foundations and research issues." MIS Quarterly, Vol. 25, No. 1, pp. 107-136.

Al-Ghassani , A. M., Kamara, J. M., Anumba C. J., and Carrillo, P. M. (2004). "An innovative approach to identifying knowledge management problems." Engineering, Construction and Architectural Management, Vol. 11, No. 5, pp. 349-357.

Arif, M., Egbu, C., Alom, O., and Khalfan, M. (2009). "Measuring knowledge retention." Engineering, Construction and Architectural Management, Vol. 16, No. 1, pp. 92-108.

Caldas, C. H., Gibson, G. E. Jr., Weerasooriya, R., and Yohe, A. M. (2009). "Identification of effective management practices and technologies for lessons learned programs in the construction industry." J. Constr. Engrg. and Mgmt., Vol. 135, No. 6, pp. 531539.

Camp, R. (1989). Benchmarking: The search for industry best practices that leads to superior performance, ASQC Quality Press, Milwaukee, Wisconsin.

Carrillo, P. and Chinowsky, P. (2006). "Exploiting Knowledge management: The construction and engineering perspective." Journal of Management in Engineering, ASCE, Vol. 22, No. 1, pp. 2-10.

Carrillo, P. M., Robinson, H. S., Al-Ghassani, A. M., and Anumba, C. J. (2004). "Knowledge management in UK construction: Strategies, resources and barriers." Project Management Journal, Vol. 35, No. 1, pp. 46-56.

Cha, H. S. and O'Connor, J. T. (2006). "Characteristics for leveraging value management processes on capital facility projects." Journal of Management in Engineering, Vol. 22, No. 3, pp. 135-147.

Chen, C. J. and Huang, J. W. (2007). "How organizational climate and structure affect knowledge management." Int. Journal of Infor- mation Management, Vol. 27, No. 2, pp. 104-118.

Chen, M. Y., Huang, M. J., and Cheng, Y. C. (2009). "Measuring knowledge management performance using a competitive perspective". Expert Systems with Applications, Vol. 36, No. 4, pp. 84498459.

Chinowsky, P. and Carrillo, P. (2008). “A strategic argument for knowledge management." Proceedings of Leadership and Management in Construction (LEAD), South Lake Tahoe, CA, pp. 1-11.

Chuang, S. H. (2004). "A resource-based perspective on knowledge management capability and competitive advantage: An empirical investigation." Expert Systems with Applications, Vol. 27, No. 3, pp. 459-465.

Cortes, E. C., Saez, P. Z., and Ortega, E. P. (2007). "Organizational structure features supporting knowledge management process." Journal of Knowledge Management, Vol. 11, No. 4, pp. 45-47.

Daft, R. L. (1995). Organization theory and design, St. Paul: West Publishing Company.

Dana, L-P., Korot, L., and Tovstiga, G. (2005). "A cross-national comparison of knowledge management practices." International Journal of Manpower, Vol. 26, No. 1, pp. 10-22.

Davenport, T. H. and Prusak, L. (1998). Working knowledge: How organizations manage what they know, Cambridge, MA: Harvard Business School Press.

Deng W. J., Kuo, Y. F., and Chen W. C. (2008). "Revised importanceperformance analysis." The service Industries Journal, Vol. 28, No. 1, pp. 37-51.

Drucker, P. F. (1998). The coming of the new organization, Harvard Business Review on Knowledge Management, Harvard Business School Press, pp. 1-19.

Drucker, J., White, G., Hegewisch, A., and Mayne, L. (1996). "Between soft and hard HRM." Construction Management and Economics, Vol. 14, No. 5, pp. 405-416.

Egbu, C. O. (2004). "Managing knowledge and intellectual capital for improved organizational innovations in the construction industry." Engineering, Construction and Architectural Management, Vol. 11, No. 5, pp. 301-315.

Fang, D. P., Huang, X. Y., and Hinze, J. (2004). "Benchmarking studies on construction safety management in China." Journal of Construction Engineering and Management, Vol. 130, No. 3, pp. 424-432.

Fong, P. S. W. and Chu, L. (2006). "Exploratory study of knowledge sharing in contracting companies: A socio-technical perspective." $J$. Constr. Engrg. and Mgmt., Vol. 132, No. 9, pp. 928-939.

Garver, M. S. (2003). "Best practices in identifying customer driven improvement opportunities." Industrial Marketing Management, Vol. 32, No. 6, pp. 455-466.

Garvin, D. A. (1998). Building a learning organization, Harvard Business Review on Knowledge Management, Harvard Business School Press, pp. 47-80.

Ghiselli, E. E., Campbell, J. P., and Zedeck, S. (1981). Measurement theory for the behavioral sciences, San Francisco: W. H. Freeman and Company.

Ghosh, B. and Scott, J. E. (2007). "Effective knowledge management systems for a clinical nursing setting." Information Systems Management, Vol. 24, No. 1, pp. 73-84.

Gold, A. H., Malhotra, A., and Segars, A. H. (2001). "Knowledge management: An organizational capabilities perspective." Journal of Management Information Systems, Vol. 18, No. 1, pp. 185-214.

Hansen, M. T., Norhia, N., and Tierney, T. (1999). "What's your strategy for managing knowledge?" Harvard Bus. Rev., Vol. 77, No. 2, pp. 106-116. 
Huber, G. P. (2001). "Transfer of knowledge management systems." European Journal of Information Systems, Vol. 10, No. 2, pp. 72-79.

Inkpen, A. (1996), "Creating knowledge through collaboration." California Management Review, Vol. 39, No. 1, pp. 123-140.

Ishikawa, A. and Naka, I. (2007). Knowledge management and risk strategies, Singapore: World Scientific Publishing Co. Pte. Ltd.

Kale S. (2009). "Fuzzy intellectual capital index for construction firms." Journal of Construction Engineering and Management, Vol. 135, No. 6, pp. 508-517.

Kamara, J. M., Anumba, C. J., and Carrillo, P. M. (2002) "A CLEVER approach to selecting a knowledge management strategy." International Journal of Project Management, Vol. 20, No. 3, pp. 205211.

Kululanga, G. K. and McCaffer, R., (2001). "Measuring knowledge management for construction organizations." Engineering Construction and Architectural Management, Vol. 8, No. 6, pp. 346-354.

Lam, E. W. M., Chan, A. P. C., and Chan, D. W. M. (2004). "Benchmarking design-build procurement systems in construction." Benchmarking: An International Journal, Vol. 11, No. 3, pp. 287-302.

Lee, H and Choi, B. (2003). "Knowledge management enablers, processes and organizational knowledge." Journal of Management Information Systems, Vol. 20, No. 1, pp. 179-228.

Luu, V. T., Kim, S. Y., and Huynh, T A. (2008). "Improving project management performance of large contractors using benchmarking approach." International Journal of Project Management, Vol. 26, No. 7, pp. 758-769.

Maqsood, T., Walker, D. H. T., and Finegan, A. D. (2007). "Facilitating knowledge pull to deliver innovation through knowledge management: A case study." Engineering Construction and Architectural Management, Vol. 14, No. 1, pp. 94-109.

Martilla J. and James, J. C. (1997). "Importance-performance analysis." Journal of Marketing, Vol. 41, No. 1, pp. 77-79.

Matusik, S.F. and Hill, C.W. L (1998). "The utilization of contingent work, knowledge creation, and competitive advantage." The Academy of Management Review, Vol. 23, No. 4, pp. 680-697.

Nahapiet, J. and Ghoshal, S. (1998). "Social capital, intellectual capital, and the organizational advantage." Academy of Management Review, Vol. 23, No. 2, pp. 242-266.

Nayir D. Z. and Uzuncarsili, U. (2007). "A cultural perspective on knowledge management: The success story of Sarkusyan company." Journal of Knowledge Management, Vol. 12, No. 2, pp. 141-155.

Nonaka, I. (1991). "The knowledge creating company." Harvard Business Review, Vol. 69, No. 6, pp/ 96-104.

Nonaka, I., Umemoto, K., and Senoo, D. (1996). "From information processing to knowledge creation: A paradigm shift in business management." Technology in Society, Vol. 18, No. 2, pp. 203-218.

Nunnally, J. C. (1978). Psychometric theory (2nd ed.), New York: McGraw-Hill.
Pathirage, C. P., Amaratunga, D. G., and Haigh R. P. (2007). "Tacit knowledge and organisational performance: Construction industry perspective." Journal of Knowledge Management, Vol. 11, No. 1, 115-126.

Pennings, J. (1992). "Structural contingency theory: A reappraisal." Research in Organizational Behavior, Vol. 14, pp. 267-309.

Robinson, H. S., Carrillo, P. M., Anumba, C. J., and Al-Ghassani, A. M. (2004). "Developing a business case for knowledge management: The IMPaKT approach." Construction Management and Economics, Vol. 22, No. 7, pp. 733-743.

Robinson, S. H., Carrillo, P., Anumba, C. J., and Al-Ghassani, A. M. (2005). "Knowledge management practices in large construction organizations." Engineering, Construction and Architectural Management, Vol. 12, No. 5, pp. 431-445.

Samuelsson, P. and Grans, P. E. (2004). "Approach for assessment and review in large construction company." Journal of Management in Engineering, Vol. 20, No. 1, pp. 2-7.

Sarrafzadeh, M., Martin, B., and Hazeri, A. (2006). "LIS professionals and knowledge management." Library Management, Vol. 27, No. 9 , pp. 621-635.

Sommerville, J. and Robertson, H. W. (2000). “A scorecard approach to benchmarking for total quality construction." International Journal of Quality Reliability Management, Vol. 17, Nos. 4/5, pp. 453-466.

Song, L., Mohamed, Y., and AbouRizk, S. M. (2009). "Early contractor involvement in design and its impact on construction schedule performance." Journal of Management, in Engineering, Vol. 25, No. 1, pp. 12-20,

Tan, H. C., Anumba, C. J., Carrillo, P. M., Bouchlaghem, D., Kamara, J., and Udeaja, C. (2010). Capture and reuse of project knowledge in construction, John Wiley and Sons Ltd., London.

Tuomi, I. (2002). "The future of knowledge management." Lifelong learning in Europe, Vol. VII, No. 2, pp. 69-79.

Wen, Y. F. (2009). "An effectiveness measurement model for knowledge management." Knowledge-Based Systems, Vol. 22, No. 5, pp. 363-367.

Wiig, K. (1993). Knowledge management foundations, Schema Press, Arlington, TX.

Wiig, K. M. (1997). "Knowledge management: Where did it come from and where will it go?" Expert Systems with Applications, Vol. 13, No. 1, pp. 1-14.

Yu, W., Chang, P., Yao, S., and Liu, S. (2009). "KVAM: Model for measuring knowledge management performance of engineering community of practice." Construction Management and Economics, Vol. 27, No. 8, pp. 733-747.

Zander, U. and Kogut, B. (1995). "Knowledge and the speed of the transfer and imitation of organizational capabilities: An empirical test." Organization Science, Vol. 6, No. 1, pp. 76-92. 


\section{Appendix. A Sample of Questionnaire Items}

\begin{tabular}{c|l}
\hline \multicolumn{1}{c|}{ Research Construct } & \multicolumn{1}{c}{ Item* } \\
\hline \multirow{3}{*}{ Knowledge Acquisition Process } & $\begin{array}{l}\text { My firm is able to... } \\
\text { Use feedback from projects to improve subsequent projects } \\
\text { Generate new knowledge from existing knowledge } \\
\text { Acquire knowledge about its clients. }\end{array}$ \\
\hline \multirow{3}{*}{ Knowledge Conversion Process } & $\begin{array}{l}\text { My firm is able to... } \\
\text { Transfer organizational knowledge to individuals } \\
\text { Absorb knowledge from individuals into firm } \\
\text { Integrate different sources and types of knowledge. }\end{array}$ \\
& My firm is able to... \\
& Apply knowledge learned from mistakes \\
& Take advantage of new knowledge \\
& Match sources of knowledge to problems and challenges. \\
\hline \multirow{2}{*}{ Knowledge Application Process } & My firm is able to... \\
& Protect knowledge from inappropriate use inside the firm \\
& Protect knowledge from theft from outside the firm \\
& Restrict access to specific sources of knowledge. \\
\hline
\end{tabular}

In my firm employees are encouraged to...

Organizational Culture $\quad$ Find new methods for performing a task

Interact with their colleagues

Suggest ideas for new opportunities

\begin{tabular}{cl}
\hline \multirow{2}{*}{ Information Technology } & $\begin{array}{l}\text { My firm has technology to... } \\
\text { Collaborate with other persons inside the firm. } \\
\text { Map the location of specific types of knowledge. } \\
\text { Retrieve and use knowledge about its operations/processes. }\end{array}$ \\
\hline \multirow{2}{*}{ Organizational Structure } & $\begin{array}{l}\text { My firm's organizational structure... } \\
\text { Facilitates the creation of new knowledge } \\
\text { Promotes the interaction and sharing of knowledge. }\end{array}$ \\
& Facilitates the discovery of new knowledge \\
\hline \multirow{2}{*}{ Knowledge Management Effectiveness } & $\begin{array}{l}\text { Over the last three years, my firm has improved its ability to... } \\
\text { Streamline its construction operations and processes. } \\
\text { Enhance the quality of contracting services and constructed facilities } \\
\text { Introduce innovative construction methods/contracting services. }\end{array}$ \\
\hline
\end{tabular}

* Source Gold et al., 2001; Lee and Choi 2003. 